\title{
Preliminary Experimental Study and Numerical Simulations on Suppressing Spray Bitumen Fire with Water Mist in a Confined Space
}

\author{
L. W. PAN ${ }^{1,2}$, Q.W. LI ${ }^{1}$, S. M. LO ${ }^{2}$, G. X. LIAO $^{1}$ and J. QIN ${ }^{1}$ \\ ${ }^{1}$ State Key Laboratory of Fire Science, University of Science and Technology of China, Hefei, \\ Anhui, China \\ ${ }^{2}$ Department of Building and Construction, City University of Hong Kong, Kowloon, Hong Kong
}

\begin{abstract}
Spray bitumen fires often occur in buildings and industrial processes. To investigate this type of hazard, the burning behavior of this flammable mixture was tested under practical conditions. Investigations of the suppression of this typical kind of fire were also included. CFD simulations were used as supplementary validation of tests that assessed the suppression of this type of fire by application of water mist. The water mist was generated from a centrifugal nozzle operating at low pressure about 1.0 MPa. The characteristics of the water mist were tested by LDV/APV system. The fuel was sprayed using the same sprayer as the sub-sprayer of the water mist nozzle. The flame structure was observed by the Thermograph (TG, SATHY6850). The various temperatures were tracked every 1 second by the K-type thermocouple. The flame suppression processes were observed and analyzed using a Charge Coupled Device (CCD) video camera. All the experiments were carried out in a $3 \mathrm{~m} \times 3 \mathrm{~m} \times 3 \mathrm{~m}$ confine space. Results indicated that the highest temperature of the spray bitumen fire was recorded in the core of the spray. The spray bitumen fire could be suppressed effectively by using the water mist fire suppression system. For lower pressure of the spray bitumen, the water mist suppression demonstrated higher efficiency. The test results showed that there was a short-lived "fire enhancement" phenomena as long as the water mist was released into the spray fire. Also, using the FDS to simulate the spray bitumen fire, we found comparative results between the numerical and experimental results.
\end{abstract}

KEYWORDS: spray bitumen fire, water mist, fire suppression, LDV/APV, CFD

\section{INTRODUCTION}

Bitumen is a very common building and industrial material. Spray bitumen, which is made of bitumen dissolved in organic solvent, is widely used in many buildings and industrial fields, e.g. roofing and waterproofing processes. It can also be used in tunnel projects as paving material. During the operational process, the high pressure bitumen mixture often comes out from a small source and generates an atomized spray, which can be easily ignited by hot surfaces, open flames or electric sparks [1-3]. The spray bitumen fire is classified as self-sustaining burning which will continue after the removal of the igniting flame [4]. The fire produced by the spray is usually torch-like, with a very high heat release rate, and poses a serious danger to personnel and equipment. Studies on techniques and methods for suppression of this special kind of fire are particularly important. However, until now there is a dearth of studies about the spray bitumen droplet group combustion characteristics, the suppression methods for spray bitumen fires, as well as limited experimental data for the performance of burning materials and fire suppression systems.

Currently, water mist fire suppression technology is one of the most effective alternatives to "halon" based gas protection systems. Water mist systems have been developed for space technology applications for events such as a flammable liquid fire, and the system demonstrates excellent efficiency for category B fires [5-6]. This system has the benefits of high efficiency, environmental acceptability, and low cost. Studies on water mist fire suppression systems are reported in the literature and include spray characteristics, spray dynamics, generation of water mist, extinguishing mechanisms, use of additives, computer modeling, application for Class A and B fires, explosion (deflagration) suppression, and applications in the special areas [7-11]. In this paper, to the use of water mist systems for suppression of spray bitumen fires is assessed. It is important to study the behavior of the burning spray bitumen under the action of water mist system to find an efficient way to control this typical fire. A better understanding of extinguishing a real spray bitumen fire would help in designing suitable systems. 


\section{SPRAY CHARACTERISTICS}

\section{Characteristics of Water mist}

The water mist system used for this study consisted of several parts. A stainless steel vessel was used as a water reservoir and a nitrogen cylinder was used to provide the operating pressure. A stainless steel filter was placed between the water reservoir and nozzle to avoid nozzle jam. The operating pressure could be adjusted using a pressure reducing valve connected with the nitrogen cylinder; it was set to below $1.0 \mathrm{MPa}$. The water mist nozzle consisted of seven sub-sprayers. The water mist was discharged from the seven subsprayers on the nozzle to form a solid water cone as shown in Fig. 1. The initial angle of the water spray near the nozzle exit was about $120^{\circ}$.

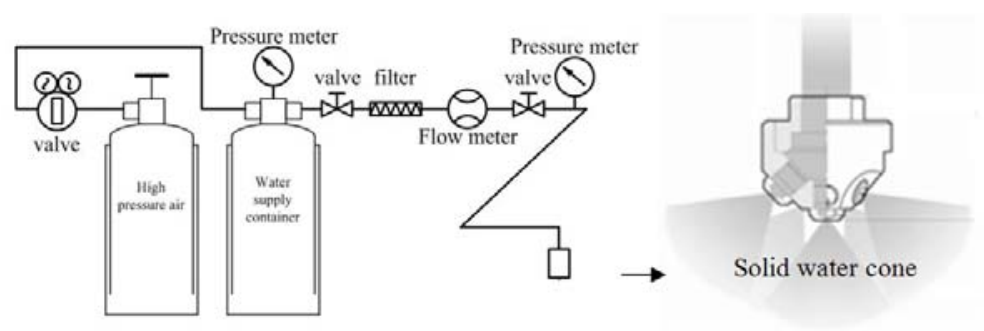

Fig. 1. Sketch of the water mist system and nozzle.

The water mist characteristics under various operating pressure were measured separately using a three dimensional Laser Doppler Velocimeter/Adaptive Phase Doppler Velocimetry (LDV/APV) system. The parameters of the LDV/APV system, as reported by Qin [9], are shown in Table 1. The measurement techniques and the system configuration have previously been described in detail [11-12]. The water mist dynamics were measured in the absence of fire. The droplet size and velocity were measured by the LDV/APV system at the cross-section $1.0 \mathrm{~m}$ below the nozzle exit. Distributions of volume mean droplet size, and mean downward velocity, along the spray radial direction under different pressures are shown in Fig. 2 and 3.

Table 1. Characteristics of the LDV/APV system

\begin{tabular}{lll}
\hline Laser & Apparatus & Innova70 \\
& Power & $5 \mathrm{~W}$ \\
& Wavelength & $514.5,488$, and $476 \mathrm{~nm}$ \\
\multirow{4}{*}{ Optical system } & Ray diameter & $1.7 \mathrm{~mm}$ \\
\multirow{3}{*}{ Data acquisition } & Transmitting focal & $300,500,1000 \mathrm{~mm}$ \\
& APV receivers focal & $310,500,1000 \mathrm{~mm}$ \\
& Signal processor & IFA 755 \\
& Measurement range & $100 \mathrm{MHz}$ \\
& Signal-noise-ratio SNR & $-12 \mathrm{~dB}$ \\
Droplet Characteristic & Data acquisition rate & High \\
& Measurement model & Non-touch and one point \\
& Velocity & -100 to $500 \mathrm{~m} / \mathrm{s}$ \\
& Diameter of droplet & $0.5-10,000 \mu \mathrm{m}$ \\
& Data accuracy & Velocity $<0.5 \%$; droplet size $<4 \%$ \\
\hline
\end{tabular}

Due to the fact that the larger droplets have greater momentum than small ones, and thus can travel further, the volume mean diameter increased from the spray centerline to the edge of the solid water cone. The volume mean diameter was in the range from $150 \mu \mathrm{m}$ to $300 \mu \mathrm{m}$, which can be classified as Class 2 water mist following the NFPA 750 Standard [13]. It's observed from the statistical mean diameter distribution that the mean droplet diameter is about $250 \mu \mathrm{m}$. 


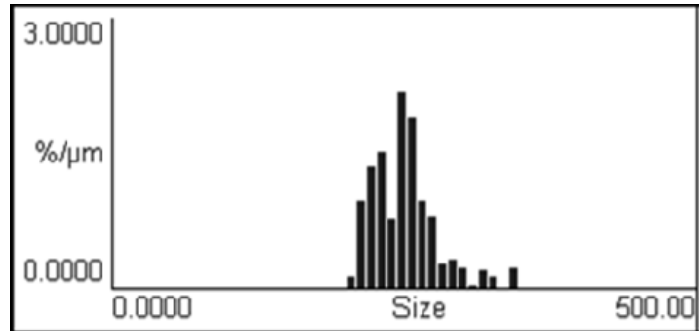

Fig. 2. Statistical mean diameter distribution of water mist versus radial distance from nozzle centerline (measured at $1.0 \mathrm{~m}$ below nozzle exit, pressure was 1.0 MPa).

The mean axial velocity was about $2 \mathrm{~ms}^{-1}$ near the centerline and $1 \mathrm{~ms}^{-1}$ near the edge; it decreased with radial distance from the centerline. Along the centerline, the initial mean velocity increased with the increase of operating pressing.

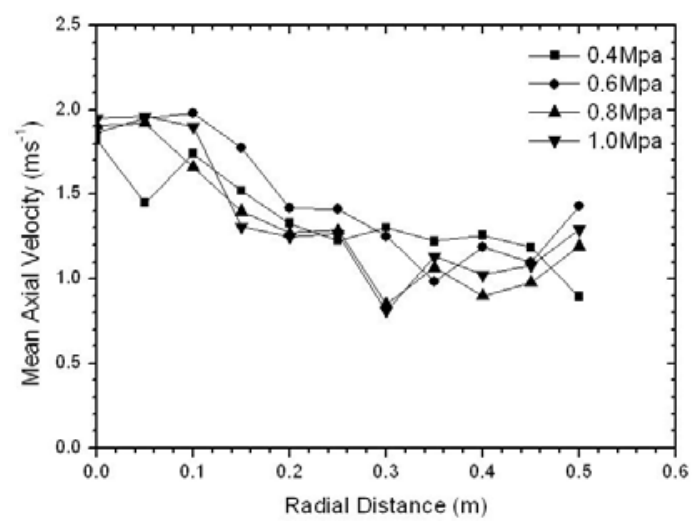

Fig. 3. Mean axial velocity of water mist versus radial distance from nozzle centerline (measured at $1.0 \mathrm{~m}$ below nozzle exit)

The water flux was measured by collecting water with containers placed on the floor, and the results are shown in Fig. 4. The water flux increased with the operating pressure, ranging from 1 to $5 \mathrm{Lmin}^{-1} \mathrm{~m}^{-}$ ${ }^{2} \mathrm{Lm}_{\mathrm{n}} \mathbf{1}^{-1} \mathrm{~m}^{-2}$ near the centerline.

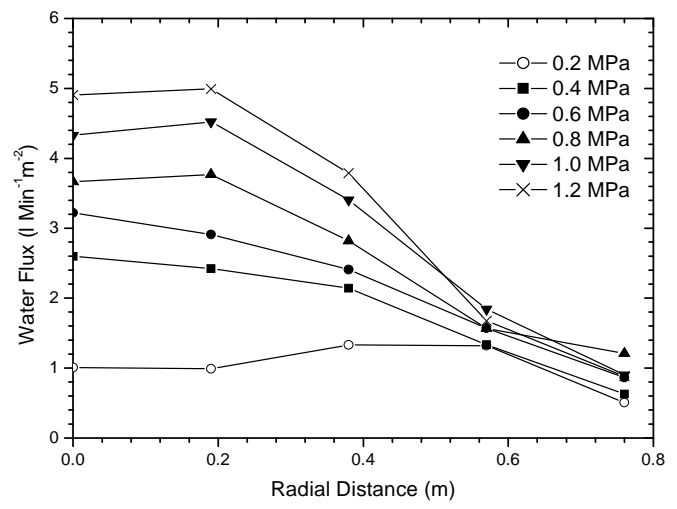

Fig. 4. Volume flux of water mist versus radial distance from nozzle centerline (measured at $1.0 \mathrm{~m}$ below nozzle exit). 


\section{Characteristics of spray bitumen}

The fuel spray system included an air compressor which supplied air at specific pressures to the fuel container. The pressure was regulated by a value on the air compressor. The fuel nozzle, with a diameter of $1 \mathrm{~mm}$, was practically identical to a single sub-head of the water mist nozzle. A schematic of the hydraulic bitumen spray system is shown in Fig. 6. The fuel pressure and fuel flux rate were chosen as critical parameters, as pointed out by Aggarwal [10] the influence of droplet diameter was neglected. The fuel flux rates for specific pressures are given in Fig. 5.

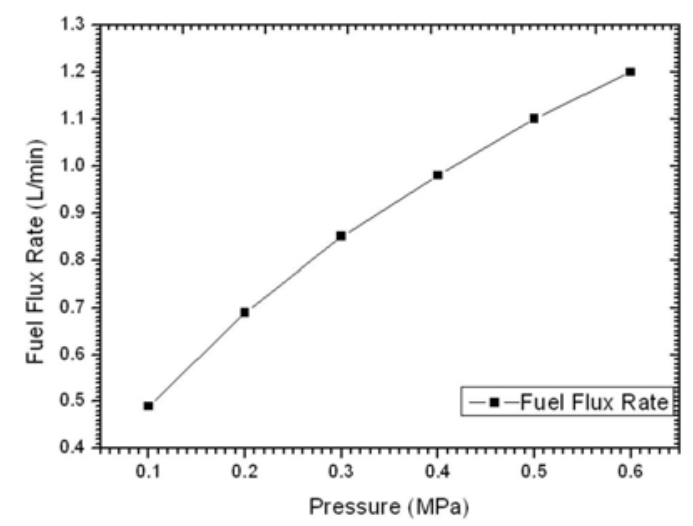

Fig.5. Fuel flux rate under different pressures.

\section{EXPERIMENTS}

\section{Spray bitumen}

The fuel consisted of $165.5 \mathrm{~g}$ of bitumen dissolved in $900 \mathrm{ml}$ of xylene $\left(\mathrm{C}_{6} \mathrm{H}_{4}\left(\mathrm{CH}_{3}\right)_{2}\right)$ solvent, and had approximately $2 \%$ contamination precipitation (18.5 g). The fuel spray system was set at the right side of the $3 \mathrm{~m} \times 3 \mathrm{~m} \times 3 \mathrm{~m}$ confined space, the height from the floor to the bitumen spray nozzle was $45 \mathrm{~cm}$, as shown in Fig. 6. The pressure of spray bitumen was set under $0.5 \mathrm{MPa}$. The fuel flux was simply modified to create a smooth fluid field at the certain pressure.

\section{Water mist system}

The water mist system was placed at the opposite side of the confined space from the bitumen spray system. The water mist was discharged from a single fluid type nozzle, which was $190 \mathrm{~cm}$ above the floor. The horizontal and vertical distance from the centerline of the water mist nozzle to the fuel nozzle was 45 $\mathrm{cm}$ and $145 \mathrm{~cm}$, respectively.

\section{Measurement instruments}

A total of five K-type thermocouples, located $45 \mathrm{~cm}$ above the floor, were placed in $15 \mathrm{~cm}$ intervals inline with the fuel spray nozzle. The thermocouples which were carefully calibrated before the experiments were labeled as TC1, TC2, TC3, TC4, and TC5 from the fuel nozzle side. The thermocouple TC3 was set directly below the water spray nozzle. A Charge Coupled Device (CCD) video camera was installed to record the suppression phenomena and take images of the flame structure. Results can be used to determine the fire suppression time with an accuracy of $\pm 0.1 \mathrm{~s}$, depending on the format of storing compressed images. The Thermograph, used to screen burning structures, was located on the same side as the CCD. All data were measured and transferred by the data acquisition system. A schematic of the test set-up and associated instruments and equipment is shown in Fig. 6. Three tests labeled as B1, B2 and B3 were carried out (See Table 2). 


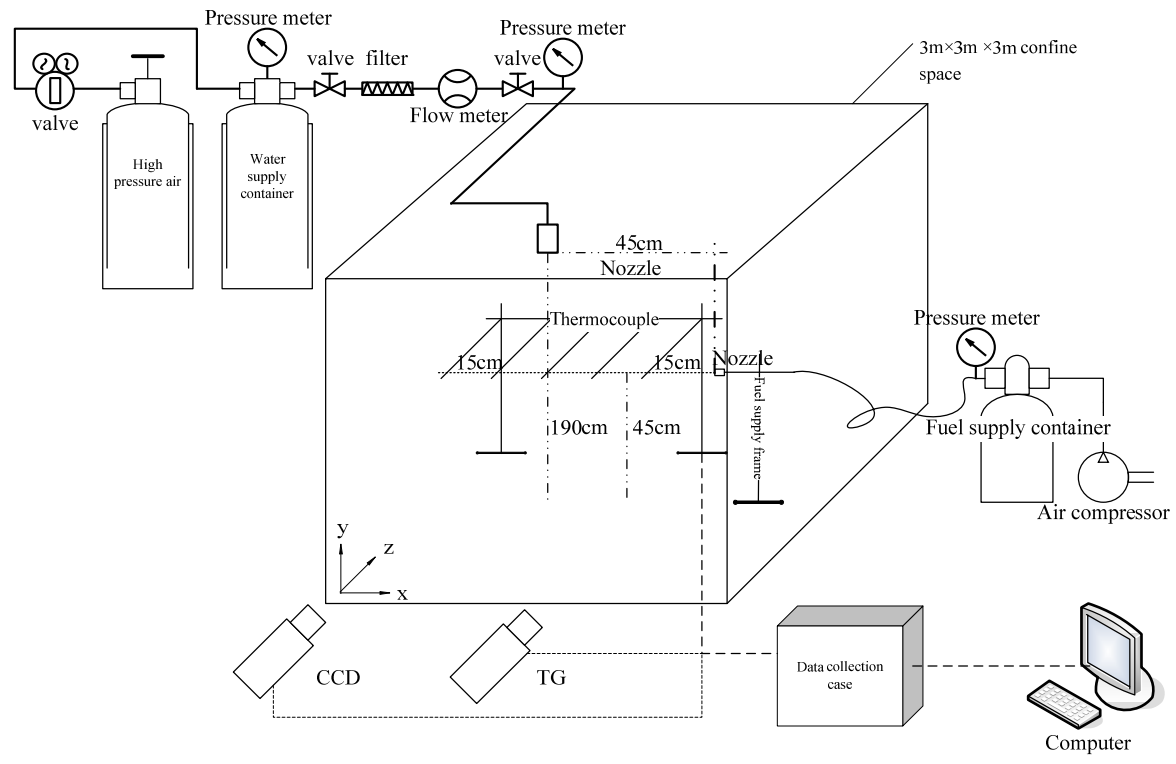

Fig. 6. Burning test instruments.

\section{TEST RESULTS}

Test B1 was conducted with bitumen spray fire operating at a pressure of $0.4 \mathrm{MPa}$, no water mist was present during this test. The bitumen spray fire was ignited at $t_{i}=5 \mathrm{~s}$; the temperature became quasi-steady after $t_{s t}=13 \mathrm{~s}$. The experimental process was recorded synchronously by the TC, CCD and TG. The structure of spray bitumen fire was analyzed by the Thermograph when the fire became quasi-steady, as shown in Fig. 7. It was found that the inner temperature of the spray fire reaches more than $977^{\circ} \mathrm{C}$, and the surrounding flame temperature was about $300^{\circ} \mathrm{C}$; the chemical reactions are concentrated in the "core" area near the orifice of the fuel nozzle. The gradient of the isotherms increased with increasing distance from the fuel nozzle. The temperature recorded by TC2 was greater than the other thermocouples, and became stable after reaching $957^{\circ} \mathrm{C}$ (see Fig. 8). The pre-burning time could be obtained by the equation $t_{\text {pre }}=t_{w}-t_{s t}=8$ s.
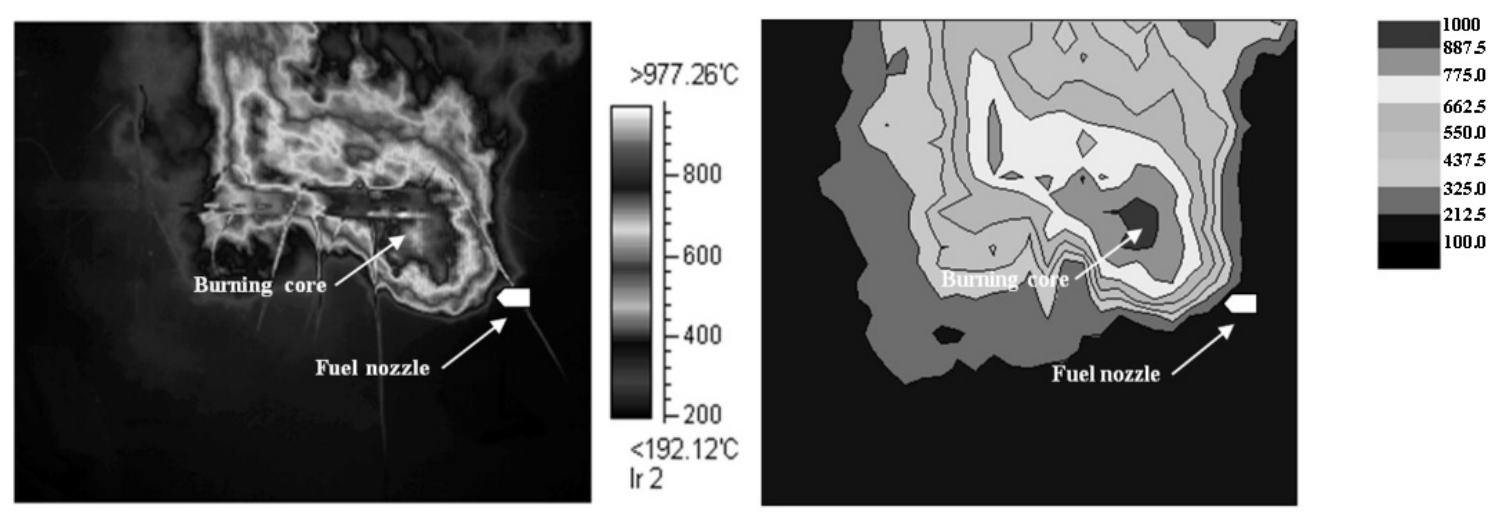

Fig. 7. The structure and isotherms of the freely burning spray bitumen fire. 


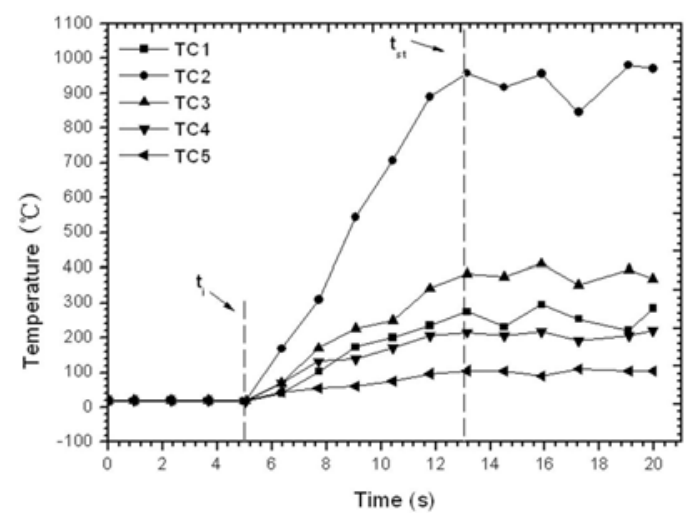

Fig. 8. Temperature results of the freely burning spray bitumen in Test B1

In test B2, the fuel pressure of the bitumen spray fire was kept at $0.4 \mathrm{MPa}$, and the water mist system, operating at a pressure of $1.0 \mathrm{MPa}$, was activated manually after the pre-burning time, $t_{\text {pre }}$, which was determined to be approximately $8 \mathrm{~s}$ in the previous test. There was a sudden "flare-up" of the spray bitumen fire observed by the CCD with an expansion of the burning flame (see Fig. 9). Simultaneously, an instant increase of the temperature was captured by the TC3 as shown in Fig. 10. The maximum temperature recorded by TC2 reached $987^{\circ} \mathrm{C}$ which is greater than the freely burning spray bitumen fire.

After the water mist activated, the temperature recorded by TC2 decreased within a short period, but the temperature recorded by TC1 continued to increase to the peak temperature $735^{\circ} \mathrm{C}$. Thermocouple data show a shifting of the peak temperature values. Video shows the watermist inflicting on the spray fire; the horizontal momentum of the water mist was greater than the fire momentum, thereby pushing the interface of the fire backwards. The burning became more stable and violent at that place. This phenomenon is shown in Fig. 11. In this test, the water mist system failed to suppress the spray bitumen fire at the beginning of water mist applications, to terminate the spray fire the fuel supply was shut off at $t_{f}=38 \mathrm{~s}$.
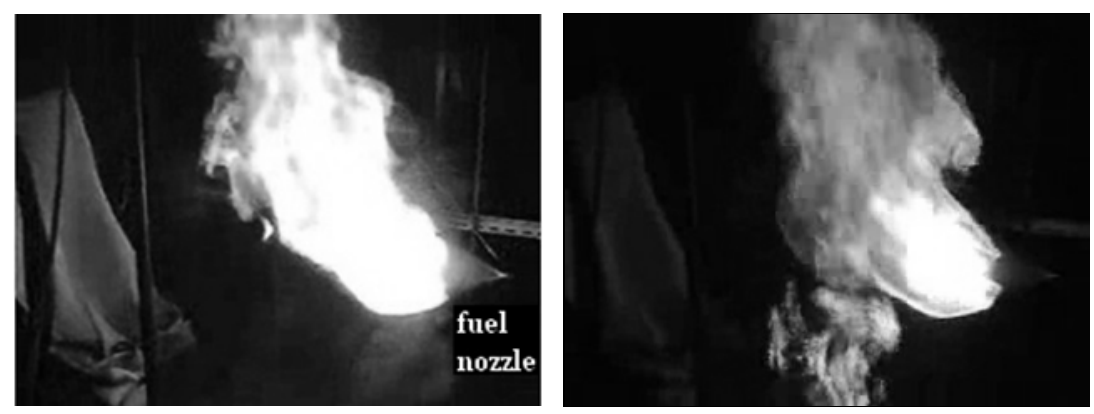

Fig. 9. The enhancement of the flame with water mist discharge - test B2.

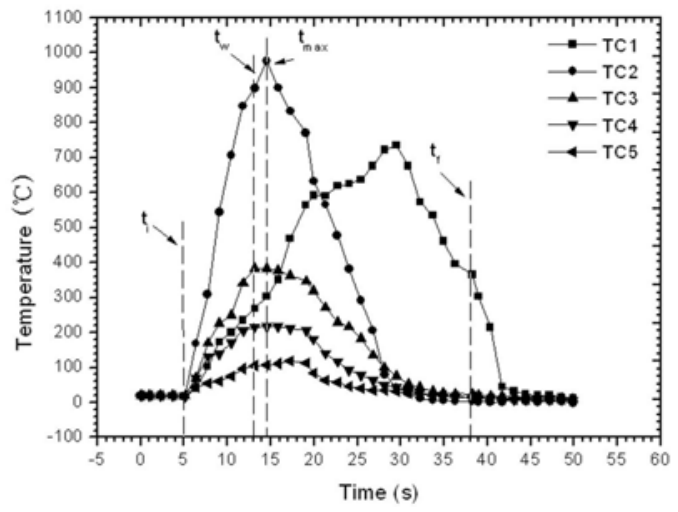

Fig. 10. Temperature results of spray bitumen fire in test B2. 


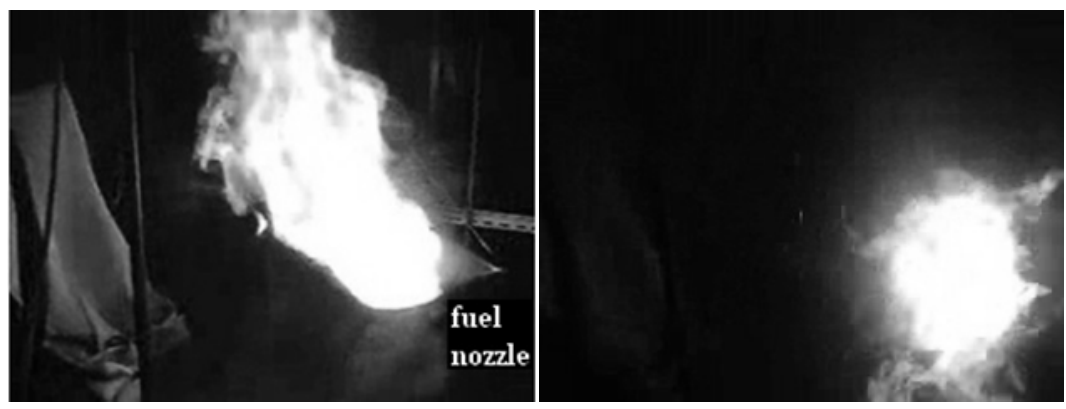

Fig. 11. Water mist blows the flame backward in test B2.

In test B3, as with test B2, the water mist system operated at a pressure of 1.0 MPa. The spray bitumen pressure was reduced to $0.3 \mathrm{MPa}$, which decreased the fuel flux and weakened the atomization of the spray bitumen droplets [10], thereby increasing the droplet size and their penetration into air. As shown in Fig. 12 , the spray distance of the spray bitumen increased with the decreased pressure, so the peak temperature $\left(\sim 732{ }^{\circ} \mathrm{C}\right.$ ) was captured by TC3, as opposed toTC2 as in test B2. The spray bitumen fire was ignited at $t_{i}=5 \mathrm{~s}$, and the temperature increased until the water mist was applied at $t_{w}=13 \mathrm{~s}$. The spray bitumen fire was successfully extinguished by the water mist system in this test.

The suppressing processes of test B3 are shown in a series of pictures in Fig. 13, the water mist system successfully extinguished the spray bitumen fire. In Fig. 14, the suppressing processes are divided into 4 periods: a) free burning time, without any external interference, and then b) fire enhancement with water mist, the sudden intensified flame appears when the mist droplets are engaged into the combustion field. c) Flame suppression with water mist which lasts about 10s, then caused d) Fire extinguishment, the visible flame disappears under the application of the water mist.

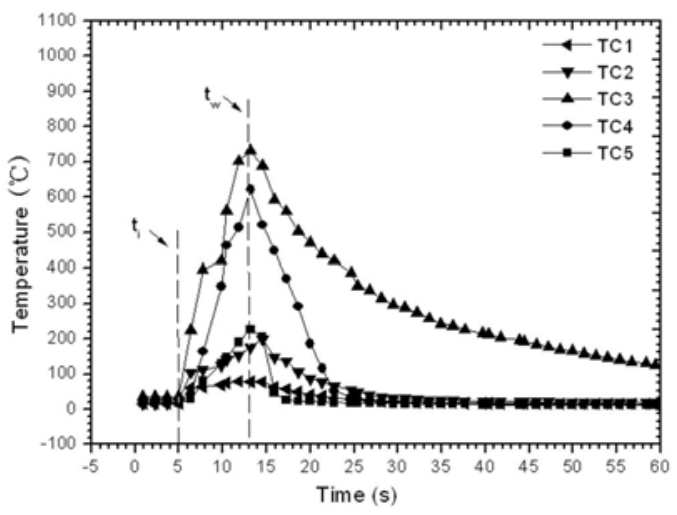

Fig. 12. Temperature results of spray bitumen fire in test B3.

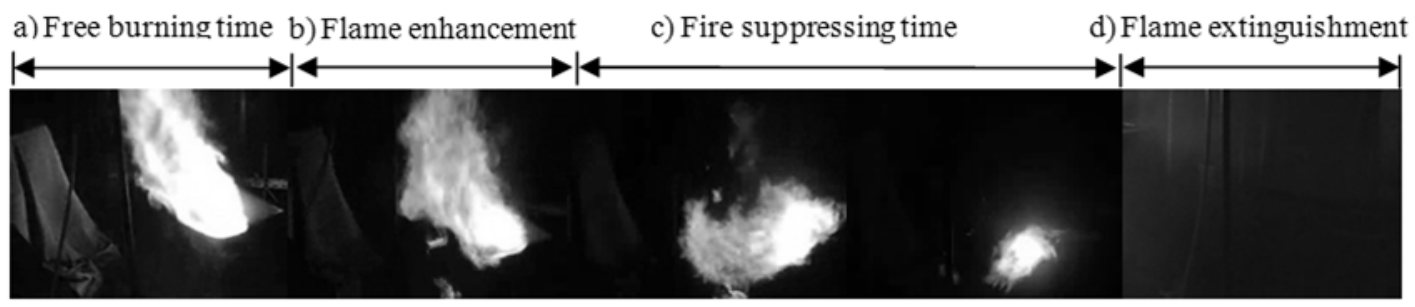

Fig. 13. The suppressing processes of spray bitumen fire in test B3.

Table 2 gives the parameters of the experimental tests and shows the critical results recorded by the CCD for each test. 
Table 2. List of critical results acquired by thermocouples and CCD.

\begin{tabular}{cccc}
\hline Critical Result & B1 & B2 & B3 \\
\hline$p_{w}$ & - & $1.0 \mathrm{MPa}$ & $1.0 \mathrm{MPa}$ \\
$p_{b}$ & $0.4 \mathrm{MPa}$ & $0.4 \mathrm{MPa}$ & $0.3 \mathrm{MPa}$ \\
$t_{i}$ & $5 \mathrm{~s}$ & $5 \mathrm{~s}$ & $5 \mathrm{~s}$ \\
$t_{w}$ & $13 \mathrm{~s}$ & $13 \mathrm{~s}$ & $13 \mathrm{~s}$ \\
$t_{\max }$ & - & $14.5 \mathrm{~s}$ & $13 \mathrm{~s}$ \\
$T_{\max }$ & $980^{\circ} \mathrm{C}$ & $997 \mathrm{o}^{\circ}$ & $732^{\circ} \mathrm{C}$ \\
$t_{f}$ & - & $38 \mathrm{~s}$ (shut off) & $24 \mathrm{~s}$ \\
\hline
\end{tabular}

\section{NUMERICAL SIMULATIONS}

FDS5 was used to simulate the interaction between the spray bitumen fire and the water mist, the basic physics are the same in both spray patterns [14]. The spray consists of a sample set of spherical droplets. The droplet size distribution is expressed in terms of its Cumulative Volume fraction (CVF), which yields a combination of log-normal and Rosin-Rammler distributions [14]. FDS also takes into consideration the absorption and scattering of thermal radiation by droplets, as well as the heat and evaporation of liquid droplets. The input data of the FDS simulation are listed in Table 3.

Table 3. List of characteristics of liquid samples.

\begin{tabular}{|c|c|c|c|}
\hline Specimen & Xylene $^{\mathrm{a}}$ & Bitumen & Mixture \\
\hline Molecular formula & $\mathrm{C}_{6} \mathrm{H}_{4}\left(\mathrm{CH}_{3}\right)_{2}$ & - & - \\
\hline Molecular weight & 106.17 & - & - \\
\hline Flash point & $27^{\circ} \mathrm{C}$ & $204^{\circ} \mathrm{C}$ & - \\
\hline Boiling point & $138^{\circ} \mathrm{C}$ & $<470^{\circ} \mathrm{C}$ & - \\
\hline Ignition Point & $500^{\circ} \mathrm{C}$ & $485^{\circ} \mathrm{C}$ & - \\
\hline Density@15ㅁ & $0.87 \mathrm{~g} / \mathrm{ml}$ & $1.15 \mathrm{~g} / \mathrm{cm}^{3}$ & $0.92 \mathrm{~g} / \mathrm{ml}$ \\
\hline Heat of Vaporization@boil & $343 \mathrm{~kJ} / \mathrm{kg}$ & - & $343 \mathrm{~kJ} / \mathrm{kg}$ \\
\hline Specific Heat@20므 & $1.65 \mathrm{~kJ} / \mathrm{kg} /{ }^{\circ} \mathrm{C}$ & - & $1.65 \mathrm{~kJ} / \mathrm{kg} /{ }^{\circ} \mathrm{C}$ \\
\hline Heat of Combustion (Net) @25॰c & $41500 \mathrm{~kJ} / \mathrm{kg}$ & - & $40000 \mathrm{~kJ} / \mathrm{kg}$ \\
\hline
\end{tabular}

${ }^{\mathrm{a}}$ Data source: Shell Chemical Data sheet, Re-issued: 15-Nov-2004

The simulation of test B2 indicates that after the activation of the water mist the HRR of the spray bitumen fire still exists and becomes disordered until the fuel is shut off (see Fig. 14). An increase in HRR was observed following the activation of the water mist in both tests B2 and B3, this phenomena is more visible in the simulation of test B3, as shown in Fig. 15. It's concluded that the water mist system suppresses the spray bitumen fire successfully. The HRR of the spray bitumen fire increases as soon as the water mist is applied to the fire, but disappears with continued application of the water mist. Figure 16 shows the simulated temperature history, the spray bitumen fire reaches the peak temperature very quickly, without any pre-burning time. As soon as the water mist is applied, the temperatures fall below $100^{\circ} \mathrm{C}$ and last for several seconds, then the fire is extinguished. 


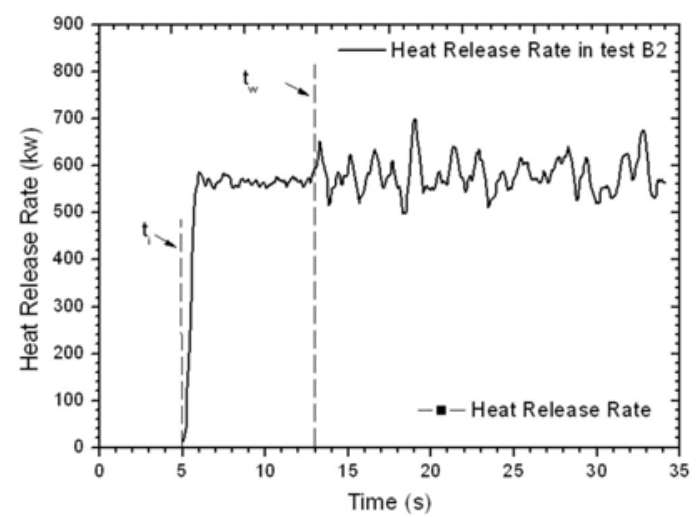

Fig. 14. The simulated heat release rate of spray bitumen fire in test B2.

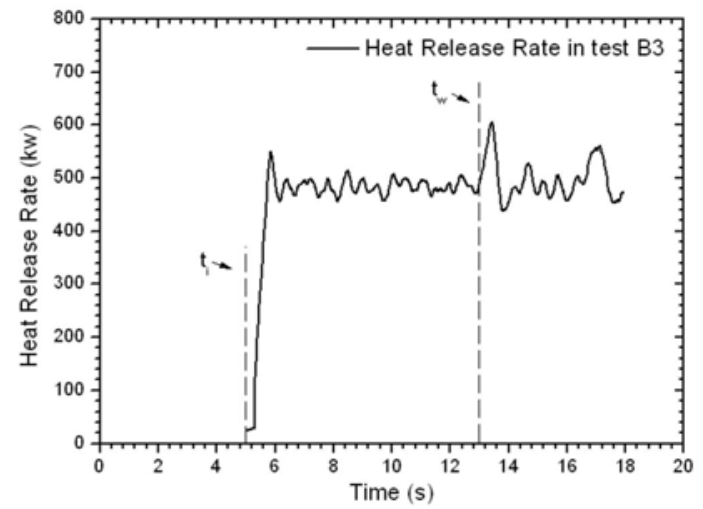

Fig. 15. The simulated heat release rate of spray bitumen fire in test B3.

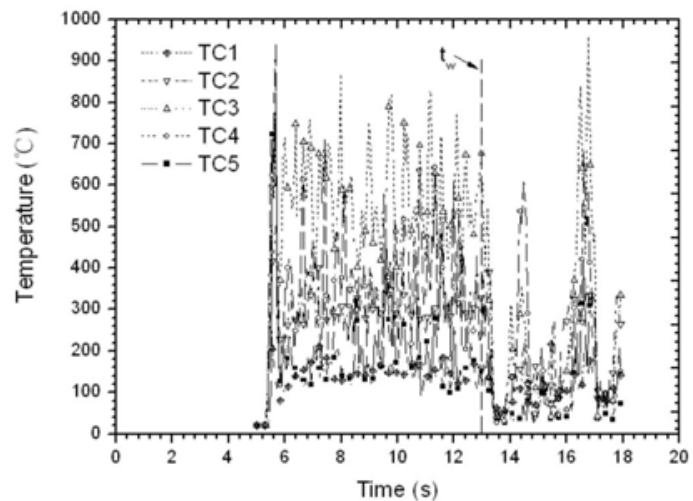

Fig. 16. The simulated temperatures of spray bitumen fire in test B3. 


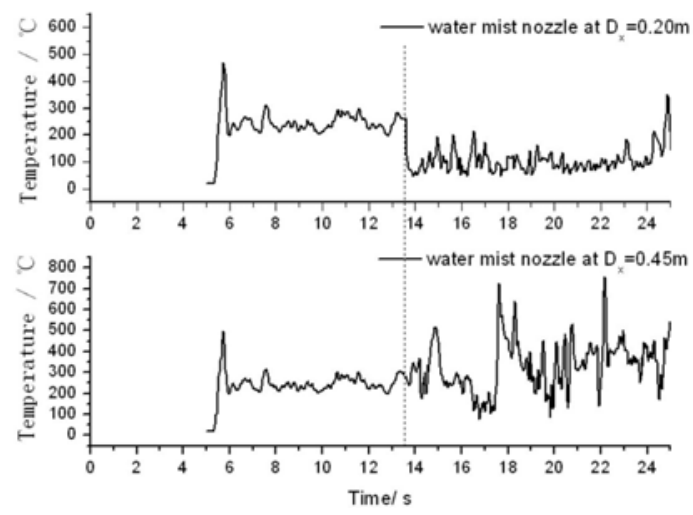

Fig. 17. Suppression efficiency comparison of two different water mist nozzle place.

\section{DISCUSSION}

In the freely burning test B1, thermograph photos of the fire were taken, which show structure of the flame clearly. The spray fire is significantly different from a pool fire. The spray fire can be defined by three regions: the fuel-rich region, where the dense fuel, and hence low oxygen density, as well as high fuel velocity create an environment not conducive to sustain burning. In this region the temperatures exceed the ignition point of the fuel; the burning region, where the fuel has good mixing with the oxidizer, most of the combustion reaction occurs in this region; the fuel-lean region, where the fuel density is attenuated by the combustion or diluted by the entrained air. The gradient of the isotherms in the fuel-rich region is greater than those in the burning region and fuel-lean region. From the temperature results of test B1, it was found that the fuel-rich region spans from the nozzle of the fuel spray nozzle to the first thermocouple $(0 \sim 15 \mathrm{~cm}$ from the nozzle), the burning region spans from the first thermocouple to the forth thermocouple $(15 \sim 60 \mathrm{~cm}$ from the nozzle), and the fuel-lean region spans from the fourth thermocouple to the end of the spray. In test B3, the burning region was shifted, spanning from the second thermocouple to the fifth thermocouple (30 75cm from the nozzle), which is shifted $15 \mathrm{~cm}$ farther away from the fuel nozzle than was observed in test B1. This indicates that reducing the pressure of the spray bitumen fire causes the combustion to occur further from the spray origin than with a higher pressure. The decrease of the spray pressure weakens the atomization of the spray bitumen droplets, which causes them to have larger diameter and mass, and thus can be transported further through the combustion area.

The water mist controls or extinguishes a fire by cooling the flame, absorbing the radiant heat, and displacing the oxygen [6]. For spray fire extinguishment, it is thought that when the water mist droplets engage the flame interface, some smaller droplets evaporate and absorb the combustion heat, which cools the flame down, then the droplets with larger volume impact and cool the burning droplets to extinguish the fire.

The flame is also extinguished when the water droplets reaches very close to the fuel spray nozzle orifice, thus limiting the space for the burning reaction. To investigate the effect of the space between the water mist nozzle and the spray bitumen nozzle on suppression efficiency, the placement of the water mist nozzle was changed in the simulation. The water mist is set at $1.0 \mathrm{MPa}$, and the spray bitumen is set at $0.4 \mathrm{MPa}$, The $D_{x}$ has been changed from $0.45 \mathrm{~m}$ to $0.2 \mathrm{~m}$. The consequence is shown in Fig. 17 .

For both test B2 and B3, A bizarre phenomenon was observed, when the water mist was applied into the spray fire there was a sudden enhancement of the fire, the flame was enlarged radially. According to Kim [15], this enhanced combustion is due to the evaporative expansion of water droplets, giving better mixing of air and fuel vapor. For spray fire, azeotropy theory was used to explain this phenomenon, the boiling point of water and bitumen solution are $100^{\circ} \mathrm{C}$ and $138^{\circ} \mathrm{C}$ separately, but when they are mixed together, the boiling point of bitumen solution reduces to $92^{\circ} \mathrm{C}$, which accelerates the boiling of the fuel droplets, and increases the burning rate of the spray fire. Significant increase of the HRR in the FDS simulations has been observed as soon as the water mist is applied. 


\section{CONCLUSIONS}

Effects of water mist on a spray bitumen fire are presented. The flame structure and burning characteristics were preliminarily tested, the most intensive chemical reactions occur in the interior of the spray fire, where the temperature reached $977^{\circ} \mathrm{C}$.

Although in test B2, the water mist failed to suppress the spray bitumen fire, it was found that there was an intensive struggle between the mist and flame. The spray fire pressure was reduced for the next test, the water mist suppressed the spray fire at a lower pressure within a short time (no more than 10s), and results indicated that the water mist system demonstrated high efficiency in suppressing the spray bitumen fire. Moreover, reducing the distance between the water mist and the fuel spray nozzle would enhance the suppression efficiency. It was validated by the CFD simulations.

The water droplet not only cools the fuel gas but also changes the evaporation rate of the fuel. The collision of the mist droplets and fuel droplets are not mentioned in the models used in FDS, the study on the mechanics of the suppression process needs further investigation, however, using CFD simulations will be convenient and helpful. Further research will concern the quantitative analysis of the ratio between the pressures of the water mist system and spray bitumen fire, and the critical suppression conditions.

\section{REFERENCES}

[1] Ulrich von Pidoll, (2001) The ignition of clouds of sprays, powders and fibers by flames and electric sparks, Journal of Loss Prevention in the Process Industries 14: 103-109. doi:10.1016/S0950-4230(00)00035-8

[2] Liming Yuan, (2005) Ignition of hydraulic fluid sprays by open flames and hot surfaces, Journal of Loss Prevention in the Process Industries 19: 353-361. doi:10.1016/j.jlp.2005.09.001

[3] Bowen, P. J., Shirvill, L. C. (1994) Combustion hazards posed by the pressurized atomization of high-flashpoint liquids, Journal of Loss Prevention in the Process Industries 7: 233-241. doi:10.1016/0950-4230(94)80071-5

[4] Ulrich von Pidoll, Helmut Kramer, (1997) Flammability of Sprays of Water-based Paints, Fire Safety Journal 29:27-39. doi:10.1016/S0379-7112(97)00002-7

[5] A. Jones and P. F. Nolan, (1995) Discussions on the use of fine water sprays or mists for fire suppression, Journal of Loss Prevention in the Process Industries, 8: 17-22. doi:10.1016/09504230(95)90057-V

[6] GRANT, G., BRENTON, J., and DRYSDALE. D, (2000) Fire suppression by water sprays, Progress in Energy and Combustion Science 26: 79-130.doi:10.1016/S0360-1285(99)00012-X

[7] J. Qin and W.K. Chow, (2005) Bench-scale tests on PMMA fires with water mist, Polymer Testing, 24:39-63. doi:10.1016/j.polymertesting.2004.07.009

[8] Gunnar Heskestad, (2003) Extinction of gas and liquid pool fires with water sprays, Fire Safety Journal, 38:301-317. doi:10.1016/S0379-7112(02)00085-1

[9] J. Qin, B. Yao and W. K. Chow, (2004) Experimental study of suppressing cooking oil fire with water mist using a cone calorimeter, International Journal of Hospitality Management, 23:545-556. doi:10.1016/j.ijhm.2004.03.001

[10] S. K. Aggarwal, (1998) A review of spray ignition phenomena: present status and future research, Progress in Energy and Combustion Science, 24: 565-600. doi:10.1016/S0360-1285(98)00016-1

[11] MAWHINNEY. J. R, DLUGOGRSKI. B. Z, KIM. A. K., A close look at the fire extinguishment properties of water mist, In Kashiwagi, T., Eds., Proceedings of the 4th International Symposium on Fire Safety Science, International Association for Fire Safety Science, 2000, pp. 47-60.

[12] W.D. Bachalo, (1993) Advances in Spray Drop Size and Velocity Measurement Capabilities for the Characterization of Fire Protection Systems, Proceedings of Water Mist Fire Suppression Workshop 1-2, pp. 75-92. 
[13] NFPA 750: Standard on water mist fire protection systems. Quincy, MA, USA: National Fire Protection Association.

[14] K. B. McGrattan, B. W. Klein, S. Hostikka, and J. E. Floyd. Fire Dynamics Simulator (Version 5), User's Guide. NIST Special Publication 1019-5, National Institute of Standards and Technology, Gaithersburg, Maryland, October 2007.

[15] Myung Bae Kim, (1996) Burning Rate of a Pool Fire with Downward-directed Sprays, Fire Safety Journal, 27:37-48. doi:10.1016/S0379-7112(96)00024-0 